\title{
Formulation and Characterization of Polyurethane Microstructures with Propolis Extract
}

\begin{abstract}
ALEXANDRA DUCA ${ }^{1}$, FLORIN BORCAN ${ }^{2 *}$, DANINA M. MUNTEAN² ${ }^{2}$ ERSILIA C. ALEXA ${ }^{3}$, CODRUTA M. SOICA ${ }^{1}$
IVictor Babes University of Medicine and Pharmacy, Faculty of Pharmacy, 2 Eftimie Murgu Sq., 300041, Timisoara, Romania; 2Victor Babes University of Medicine and Pharmacy, Faculty of Medicine, 2 Eftimie Murgu Sq.,, 300041, Timisoara, Romania 3Banat University of Agricultural Sciences and Veterinary Medicine King Michael I of Romania from Timi'oara, Faculty of Agrofood Technologies, 119, Calea Aradului, 300641, Timisoara, Romania

Propolis is a natural apicultural product derived from plant resins with impressive health benefits. Its major biologically active substances are barely soluble in water, but this could be increased by proper formulations. The aim of the present study was to obtain a transmembrane delivery system based on polyurethane microstructures for eight propolis samples collected from different regions of Western Romania and to characterize them by differential scanning calorimetry (DSC); the assessed parameters were the particle size, the polydispersity index and their clustering tendency. Polyurethane polymers based on isophorone-diisocyanate and polyethylene glycol 200/ethylene glycol were chosen as carriers for the propolis extract. A perfect inclusion of propolis inside the structures was observed for half of the samples. Particle size ranged between 504 and $621 \mathrm{~nm}$ and was confirmed by the low stability against aggregation (Zeta potential: 16.3-19.8 mV). The polydispersity index was between 0.4 and 0.7.
\end{abstract}

Keywords: propolis, polyurethane microstructures, differential scanning calorimetry, Zeta potential

The science and technology of nanomaterials (or nanotechnology) is an emerging field that allows the synthesis of compounds with improved physico-chemical properties in terms of increased reactivity, solubility and stability against oxidising agents and enzymes [1]. Propolis, a resinous aromatic mixture collected from honeybees from o variety of plants (such as poplar, birch, pine, alder, beech, chestnut, oak, eucalyptus, palm[1, 2]) has been used in the treatment of different pathological conditions, including gastrointestinal disorders (mucositis, colitis, gastritis, gastric and duodenal ulcers)[3], allergies, oral, gynecological and dermatological pathologies [4]. The major components of propolis are resins (50-70\%), waxes and fatty acids (30-50\%), pollen (5-10\%) and others [5]. In general, the main active constituents of propolis are polyphenols (flavonoids, phenolic acids, aldehydes, ketones, esters) [2]. Many biological activities have been reported for propolis, including: antiulcer[4], antioxidant, antibacterial, antifungal, antiprotozoal, anti-inflammatory, immunomodulatory, antitumoral, hepatoprotective and antidiabetic [6]. These beneficial effects of the free form of propolis are limited by its low solubility, absorption and bioavailability, and untargeted release [1]. Polymeric particles are widely used in pharmaceutical industry as delivery vehicles for drugs. They are generally recognized as safe due to their biocompatibility (being non-toxic to humans), biodegradability and storage stability; moreover, the controlled release of drug allows in many cases to achieve a target delivery resulting in an enhanced therapeutic effect [7].

Several encapsulation technologies have been used over the time to obtain nano-propolis with an improved absorption and a superior biological effects [1]. Among these are, for example, solvent emulsification-evaporation, high pressure homogenization, high-speed stirring, ultrasonication, nanoprecipitation, microemulsion-spray drying technique etc. [8]. Using a microencapsulation method based on casein micelles, Sahlan and Supardi (2013) prepared nano-propolis particles with dimensions ranging between $1.3 \mu \mathrm{m}$ and $300 \mathrm{~nm}$ with confirmed antibacterial activity [9]. Elbaz et al. (2016) obtained propolis nano-in-microparticles based on chitosan with cytotoxic effects on human liver and colorectal cancer cells (HepG2, HCT 116) that presented three-fold higher anticancer activity than free propolis [10]. Hasan et al. (2014) synthesized nanopropolis encapsulated in maltodekstrin with a size of $175 \mathrm{~nm}$, by high speed homogenization combined with solvent evaporation technique; these nanoparticles had also an improved antibacterial activity as compared to the propolis extract, on B. subtilis, S. aureus, E. coli and Salmonella sp. [11]. Afrouzan et al. (2012) prepared nanopropolis with the size between $51 \mathrm{~nm}-486 \mathrm{~nm}$, by milling media method, that presented superior antimicrobial activity against $C$. albicans and $S$. aureus when compared to propolis [12]. Nascimento et al. (2016) synthesized polymeric nanoparticles with propolis extract based on a poly-e-caprolactone-pluronic polymeric matrix, using a nanoprecipitation method (preformed polymer interfacial deposition method) with the size comprised between $208.5 \mathrm{~nm}$ and $280.2 \mathrm{~nm}$ and $\mathrm{a}$ polydispersity index variation from 0.089 to 0.169 that suggests a unimodal model (monodisperse particles); the Zeta potential of nanopropolis varied from - $12.7 \mathrm{mV}$ to $26.8 \mathrm{mV}$, these variations being explained by the polarity of the solvent, the nature and the concentration of the surfactants and the polymer in the watery and organic phase, respectively. These nanoparticles presented cytotoxic activity against Leishmania braziliensis [8]. The antimicrobial activity of propolis against $S$. aureus and $C$. albicans was increased by a proper formulation as a niosomal-based system for topical administration; propolis-loaded niosomes, with the dimension between $294 \mathrm{~nm}$ and $427 \mathrm{~nm}$, were obtained using Span 60 and cholesterol and they were included in a Carbopol P934 base. The Zeta potential of the nanoparticles ranged from - $33.2 \mathrm{mV}$ to $-38.8 \mathrm{mV}[13]$.

Polyurethanes were discovered in the 1930s by Otto Bayer, building on a reaction observed in 1849 between

* email: fborcan@umft.ro, Phone: +40 722371025

MATERIALE PLASTICE $\bullet 56$ No. $2 \diamond 2019 \quad$ http://www.revmaterialeplastice.ro 
alcohols and isocyanates with the formation of urethane (carbamate) groups. These polymeric materials are widely used as coatings, adhesives, sealants, flexible or rigid foams, elastomers and they have many applications in the biomedical field (antibacterial surfaces, catheters, cardiac patches, stents, drug delivery vehicles, coatings for breast implants etc). Polyurethane mechanical and physical properties are similar to natural tissues [14].

This research aimed to synthesize propolis-loaded polyurethane structures through a process of polycondensation combined with spontaneous emulsification and to characterize them by thermal analysis and Zetasizer measurements.

\section{Experimental part}

Reagents

Isophoronediisocyanate (IPDI), Span ${ }^{\circledR} 85$ and polyethylene-glycol (PEG 200) were purchased from Merck (Germany), acetone and ethanol from S.C. Chimreactiv S.R.L. (Bucharest, Romania), ethylene-glycol (EG) from Lach-Ner S.R.O. (Czech Republic).

\section{Preparation of extracts}

Eight grinded propolis samples collected from different regions of Western Romania during 2015-2016, were treated with $60 \%$ (v/v) ethanol (S.C. Chimreactiv S.R.L., Bucharest, Romania) to reach a concentration of $5 \%(\mathrm{~m} /$ v). The mixtures were stirred for $1 \mathrm{~h}$ using a Heidolph PROMAX 1020 platform shaker (speed setat 7 on the digital display) and afterwards they were filtered through a filter paper. Samples were stored in natural polypropylene plastic vials, in the dark, in a refrigerator, until encapsulation. No visible changes in the samples were observed during storage.

\section{Formulation of polyurethane microparticles (PU)}

The PU microstructures were synthesized following a multi-step process according to Albulescu et al. (2014) with some modifications [15]. In brief, an organic phase (1.5 mL isophorone diisocyanate - IPDI mixed with $15 \mathrm{~mL}$ acetone) was treated with an aqueous phase $(0.5 \mathrm{~mL}$ PEG 200, $1.5 \mathrm{~mL} \mathrm{EG}, 3 \mathrm{~mL} \mathrm{Span}{ }^{\circledR} 85$ and $15 \mathrm{~mL}$ distilled water) at a temperature of $50^{\circ} \mathrm{C}$, under magnetic stirring $(400-$ $600 \mathrm{rpm}$ ) for $4 \mathrm{~h}$. The two phases were prepared at 50! under constant homogenization for $20 \mathrm{~min}$. The resulted emulsions were put in Petri dishes in thin layers in order to dry at room temperature for about 3 weeks, until constant weight was reached. The final products were stored in Eppendorf tubes at room temperature till further analysis. This procedure was reproduced for every propolis extract (noted from P1 to P8) and one was done without any sample (PU 0).

\section{Thermal decomposition evaluation}

The thermal behavior of the PU structures was assessed by differential scanning calorimetry (DSC) using a MettlerToledo DSC1 instrument (Mettler-Toledo, Switzerland). Small portions of samples (between 2.1 and $3.0 \mathrm{mg}$ ) were placed in standard aluminium crucibles with pierced caps and were heated between -10 and $290^{\circ} \mathrm{C}$ (heating speed 5 degree/min) in an inert atmosphere ( $100 \mathrm{~mL} / \mathrm{min} \mathrm{Ar}$ ). Empty aluminium crucibles with pierced cap, used as reference, simultaneously undergo the same programmed time/temperature routine.

\section{Dimension and stability of PU structures}

The stability against cluster formation and particles size were measured using a Vasco Size Analyzer and a Wallis Zeta Potential Analyzer (Cordouan Technol., France). The following parameters were set for the Size Analyzer: temperature: $25^{\circ} \mathrm{C}$, time interval: $10-15 \mu \mathrm{S}$, number of channels: $380-450$, laser power: $90 \pm 3 \%$, DTC position: up, acquisition mode: continuous, analysis mode: PadeLaplace, while for the Zeta potential Analyzer it was chosen: plastic cuvettes, temperature: $25^{\circ} \mathrm{C}$, resolution: medium $-0.8 \mathrm{~Hz}$, Henry function: Smoluchowski.

\section{Results and discussions}

The thermal analysis can provide qualitative and quantitative data about the physico-chemical state of the guest inside the polyurethane capsules. A perfect inclusion of the guest inside the capsules may cause the disappearance of any exo- and endothermic peaks (as it is the case of samples P3, P4, P5 and P6 who were very similar to the reference sample - PU 0). The large endothermic peak of samples P1 and P8 represents the water evaporation, while the other peaks of samples P1, P2, P7 and P8 indicate a low efficiency of encapsulation (the exothermic behavior of these samples between 220 and $290^{\circ} \mathrm{C}$ is due to the guest degradation) (fig. 1).

Regardind the size and stability of synthesized microstructures, no important differences were observed between the samples (tble 1).

The dimension of particles is influenced by the molecular weight of polyols [16]. The diameterof synthesized PU particles ranged between 498 and $621 \mathrm{~nm}$, the particles filled with propolis extracts having larger sizes compared to PU 0 , due to the intercalation of active substances from extract inside the polymer chain. The particle size distribution was evaluated by the

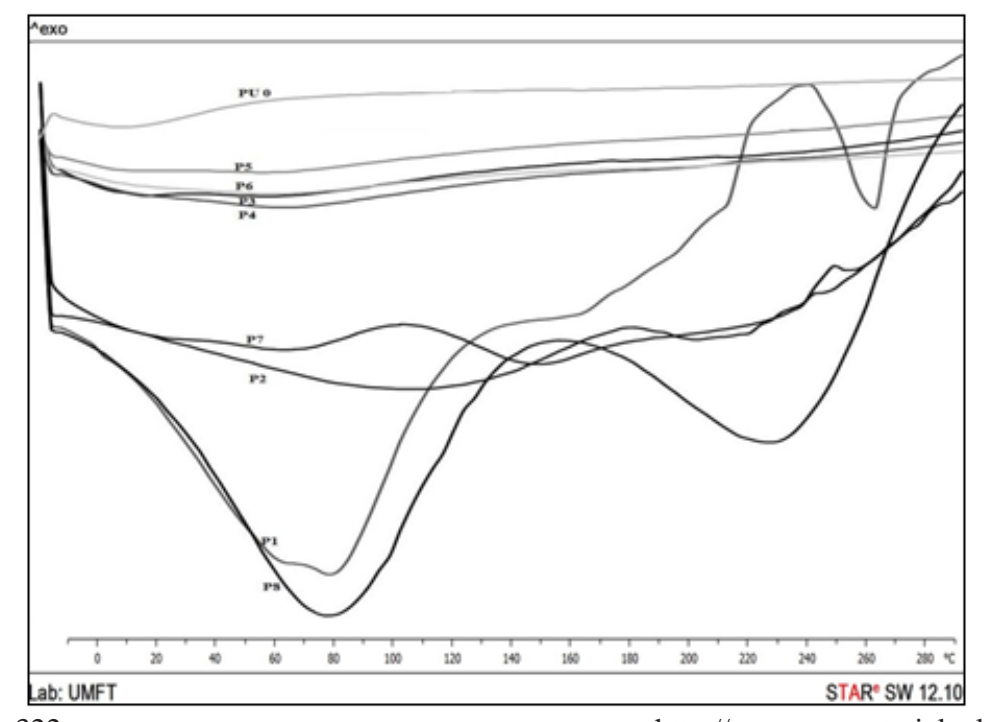

Fig. 1. The DSC curves of empty microstructures sample (PU 0 ) and of the eight microstructures samples with propolis extract $(\mathrm{P} 1 \rightarrow \mathrm{P} 8)$ 
Table 1

PARTICLE SIZE AND STABILITY AGAINST CLUSTER FORMATION OF PU STRUCTURES

\begin{tabular}{|c|c|c|c|}
\hline Sample & $\begin{array}{c}\text { The size of } \\
\text { particles } \\
(\mathrm{nm})\end{array}$ & $\begin{array}{c}\text { The } \\
\text { polydispersity } \\
\text { index } \\
\text { (PDI) }\end{array}$ & $\begin{array}{c}\text { Zeta } \\
\text { potential } \\
(\mathrm{mV})\end{array}$ \\
\hline PU 0 & $498 \pm 21$ & 0.4 & $+21.9 \pm 1.2$ \\
\hline P1 & $562 \pm 17$ & 0.7 & $+16.3 \pm 0.9$ \\
\hline P2 & $504 \pm 15$ & 0.6 & $+17.7 \pm 0.8$ \\
\hline P3 & $549 \pm 23$ & 0.5 & $+19.1 \pm 1.1$ \\
\hline P4 & $597 \pm 11$ & 0.6 & $+19.7 \pm 0.7$ \\
\hline P5 & $558 \pm 14$ & 0.4 & $+18.5 \pm 0.9$ \\
\hline P6 & $621 \pm 19$ & 0.5 & $+16.8 \pm 1.3$ \\
\hline P7 & $609 \pm 13$ & 0.7 & $+19.8 \pm 1.2$ \\
\hline P8 & $577 \pm 16$ & 0.4 & $+18.6 \pm 0.8$ \\
\hline
\end{tabular}

measurement of the polydispersity index (PDI); it varied from 0.4 to 0.7 , indicating a highly polydisperse system [17].

In order to assess the colloidal particles stability, Zeta (æ) potential can be measured. A stable suspension is characterized by a raised value of this electrokinetic potential, either negative or positive $( \pm 30 \mathrm{mV})$ [8]. For unstable particles, Zeta potential values vary between -30 $\mathrm{mV}$ and $+30 \mathrm{mV}$ [18]. The propolis filled-particles presented poor stability against cluster formation (Zeta potential from +16.3 to $+19.8 \mathrm{mV}$ ); a medium stability was observed for the empty capsules $(+21.9 \mathrm{mV})$. A value of Zeta potential between $20-30 \mathrm{mV}$ is suggestive for a medium stability of colloidal particles with a mild agglomeration tendency [19].

\section{Conclusions}

Polyurethane microcapsules with eight differentpropolis extracts were synthesized and characterized. Half of the samples presented high thermal stability yet the system was highly polydisperse (polydispersity index between 0.4 and 0.7 ). The size of the propolis filled-structures varied from $504 \pm 15$ to $621 \pm 19 \mathrm{~nm}$ ) and they displayed a rather low stability against cluster formation. These types of the micro-propolis will be further tested as compared to free propolis.

\section{References}

1. SEVEN, P.T., SEVEN, I., BAYKALIR, B.G., MUTLU, S.I., SALEM, A.Z.M., Ital. J. Anim. Sci., 17, 4, 2018, p.921.
2.ANJUM, S.I., ULLAH, A., KHAN, K.A., ATTAULLAH, M., KHAN, H., ALI, H., BASHIR, M.A., TAHIR, M., ANSARI, M.J., GHRAMH, H.A., ADGABA, N.,DASH, C.K., Saudi. J. Biol. Sci., 2018, (article in press).

3.DA SILVA, L.M., DE SOUZA, P., AL JAOUNI, S.K., HARAKEH, S., GOLBABAPOUR, S., S. DE ANDRADE, S.F., Evid. Based. Complement. Alternat. Med., 2018, Article ID 2035820, 2018,

4.PASUPULETI, V.R., SAMMUGAM, L., RAMESH, N., GAN, S.H., Oxid. Med. Cell. Longev.,2017, Article ID 1259510,2017.

5. AHANGARI, Z., NASERI, M., VATANDOOST, F., Iran. Endod. J.,13, no. 3, p. 285, 2018.

6. WAGH, V.D., Adv. Pharmacol. Sci.,2013, Article ID 308249,2013.

7. AZEVEDO, L.F.,DA FONSECASILVA, P., BRANDAOM.P., DA ROCHA, L.G., R., ARAGAO, C.F.S., DA SILVA S.A.S., PORTO, I.C.C.M., BASILICOJUNIOR, I.D., DA SILVA FONSECA, E.J., DE MOURA, M.A.B.F., DO NASCIMENTO, T.G.,J. Apic. Res., 57, no. 2, 2018, p. 255.

8. DONASCIMENTO, T.G., DA SILVA, P.F., AZEVEDO, L.F.,DAROCHA, L.G., DE MORAES PORTO, I.C., LIMA E MOURA, T.F., I. D. BASÍLIOJÚNIOR, I.D., GRILLO, L.A., DORNELAS, C.B., FONSECA, E.J., DE JESUS OLIVEIRA, E., ZHANG, A.T., WATSON,D.G.,Nanoscale Res. Lett., 11, no. 1, 2016, p. 301.

9. SAHLAN M., SUPARDI, T., Int. J. Pharma. Bio. Sci., 4, no. 1, 2013, p. 297.

10. ELBAZ, N.M., KHALIL, I.A., ABD-RABOU, A.A., EL-SHERBINY, I.M., Int. J. Biol. Macromol., 96, 2016, p. 254.

11. HASAN, A.E.Z., AMBARSARI, L., WIDJAJA, W.L., PRASETYO, R., IOSR J. Pharm., 4, no. 12, 2014, p. 01.

12.AFROUZAN, H., AMIRINIA, C., MIRHADI, S.A., EBADOLLAHI, A., VASEJI, N., TAHMASBI, G., Afr. J. Microbiol. Res., 6, no. 2, 2012, p. 421. 13. PATEL, J., KETKAR, S., PATIL, S., FEARNLEY, J., MAHADIK, K.R., PARADKAR, A.R., Integr. Med. Res., 4, 2015, p. 94.

14. JOSEPH, J., PATEL, R.M., WENHAM, A., SMITH, J.R., T. I. Met. Finish., 96, no. 3, 2018, p. 121.

15. ALBULESCU, R.C., BORCAN, F., PAUL, C., VELEA, I., PUIU, M.,ICPJ , 3, no. 6, 2014, p. 275.

16. BOUCHEMAL, K., BRIANCON, S., PERRIER, E., FESSI, H., BONNET, I., ZYDOWICZ, N., Int. J. Pharm., 269, no. 1, 2004, p. 89.

17. BHATTACHARJ EE,S., J. Control Release, 235, 2016, p. 337.

18. TRANDAFIRESCU, C., LEDETI, I., CORICOVAC, D.E., SOICA, C.M., PNZARU, I., DEHELEAN, C.A., IACOB, R.E., BORCAN, F.,Mat. Plast., 53, no. 2, 2016, p. 205.

19. SUSAN, R., PANA, R., SAS, I.T., BORCAN, F., ARDELEAN, E., ENACHE, A., PNZARU, I., Mat. Plast., 55, no. 1, 2018, p. 91.

$\overline{\text { Manuscript received: } 9.03 .2019}$ 